\title{
Response of Verticillium Species to Griseofulvin
}

\author{
By I. ISAAC AND J. M. MILTON \\ University of Wales, University College of Swansea \\ (Accepted for publication 3 September 1966)
}

\begin{abstract}
SUMMARY
Griseofulvin induced various morphological abnormalities of the hyphae of Verticillium albo-atrum and $V$.dahliae. The growth-response curves obtained were unusual, and were due to the behaviour of the antibiotic. Repeated subcultivation of mycelium on Dox medium agar containing constant concentrations of griseofulvin produced trained mycelium which was however unstable. True adaptation of $V$. alboatrum was obtained when faster growing sectors of mycelium were produced at the periphery of inhibited colonies. This adapted mycelium showed decreased morphological abnormality but still showed marked inhibition of growth. Chitin production, estimated as glucosamine, following growth in the presence of griseofulvin appeared to be stimulated in the walls of non-adapted mycelium, but remained at a relatively constant value in the walls of the adapted mycelium.
\end{abstract}

\section{INTRODUCTION}

The antibiotic griseofulvin was isolated by Oxford, Raistrick \& Simonart (1939) as a metabolic product of Penicillium griseofulvum Dierckx. In 1946, Brian, Curtis \& Hemming obtained by chloroform extraction of the culture medium or mycelium of $P$. nigricans a substance which they termed 'curling factor' because of the morphological abnormalities it induced on the germ tubes of Botrytis allii. Later, Grove \& McGowan (1947) showed that griseofulvin and 'curling factor' were one and the same substance. Griseofulvin was also shown to cause morphological abnormalities of the hyphae of other fungi (Brian, 1949; Napier, Turner \& Rhodes, 1956; Aytoun, 1956), although only fungi with cell walls based on chitin appeared to be affected. Fungi with cell walls based on cellulose, e.g. Oomycetes, were apparently unaffected.

The nature of the morphological responses of sensitive fungi to griseofulvin is still unresolved. Brian $(1949,1960)$ considered that they were caused by the antibiotic decreasing the rigidity of the cell wall in the region of the hyphal tip so that the internal pressures could no longer be supported by the weakened membranes; he also suggested that griseofulvin interfered with the biosynthesis of cell-wall chitin. Rhodes (1962) suggested that griseofulvin might become incorporated into the cell wall to form a modified chitin. El-Nakeeb \& Lampen (1965), who used griseofulvin ${ }^{-3} \mathrm{H}$, reported that it was taken up by sensitive fungi and formed complexes with nucleic acids and proteins.

Verticillium species have been shown by Brian (1949) and Napier et al. (1956) to be sensitive to griseofulvin, and the latter workers found that $V$. albo-atrum and $V$.dahliae reacted differently in their sensitivity.

The present paper considers some responses to griseofulvin of $V$. albo-atrum and $V$. dahliae in culture. 


\section{METHODS}

Organisms used. The isolates used were Verticillium albo-atrum (an unusually slowgrowing strain when on Dox medium agar) isolated from potato, a hyaline variant of it (=V.albo-atrum var.) and $V$. dahliae isolated from Antirrhinum. Stock cultures were maintained on test-tube slopes of Dox medium agar stored at room temperature.

For agar media and liquid media, the inocula were mycelial discs, $3 \mathrm{~mm}$. diameter, consisting of conidia, mycelium and resting bodies of the test fungus, cut from just inside the leading edge of 2-week cultures on Dox medium agar. Liquid cultures were incubated at $25^{\circ}$ in the dark without shaking for 15 days.

Chemicals. All chemicals used were obtained from British Drug Houses Ltd. (B.D.H.) and were of A.R. grade where available. The griseofulvin used was kindly supplied by Dr A. Rhodes (Glaxo Ltd.) and by Professor P. W. Brian (University of Glasgow).

Before use all glassware was cleaned with chromic acid + sulphuric acid, thoroughly rinsed with tap water and then with distilled water.

Media. In all experiments Dox medium (containing $1.5 \%$ sucrose, $0.2 \%$ sodium nitrate, $0.05 \%$ magnesium sulphate, $0.05 \%$ potassium chloride, $0.1 \%$ potassium dihydrogen orthophosphate, $0.001 \%$ ferrous sulphate, $2 \%$ agar) was used. For liquid cultures $25 \mathrm{ml}$. medium was dispensed into $250 \mathrm{ml}$. Pyrex conical flasks. Agar media were poured to a depth of about $3 \mathrm{~mm}$. into sterile Pyrex Petri dishes $9 \mathrm{~cm}$. diameter.

Where griseofulvin was to be incorporated into media a dilution method of preparation was used, namely, a known weight of griseofulvin was shaken for $3 \mathrm{hr}$ with a known volume of $50 \%(\mathrm{v} / \mathrm{v})$ ethanol in water and a given volume of this solution (or suspension) removed and added to the growth medium to give the required concentration, in each case $1 \%(\mathrm{v} / \mathrm{v})$ ethanol, in the medium. The remainder of the solution was diluted with a given volume of $50 \%(\mathrm{v} / \mathrm{v})$ ethanol in water, shaken for $3 \mathrm{hr}$ and a volume of this dilution removed and added to the growth medium. This process was repeated to give the range of griseofulvin concentrations required.

Recording of growth. Growth on Dox agar was recorded by measuring the diameters of colonies in two directions at right angles and taking the mean of six replicates. The mycelia from liquid cultures were collected on previously dried and weighed filter papers, washed thoroughly with distilled water and dried for $24 \mathrm{hr}$ at $85^{\circ}$. The mean dry weight of ten replicate cultures was determined.

Test of the effect of griseofulvin on the germination of conidia. Glass microscope slides were placed inside $9 \mathrm{~cm}$. diam. Petri dishes which were then sterilized at $300^{\circ}$ for $6 \mathrm{hr}$. The slides were then covered with a thin layer of Dox medium agar containing griseofulvin and when cool dipped in a spore suspension of the test fungus prepared in sterile distilled water. The effect of the antibiotic on the germination and morphology of the germ tubes was observed after incubating the slides in the Petri dishes at $25^{\circ}$ for $20 \mathrm{hr}$.

Spectrophotometric determination of griseofulvin. Griseofulvin in solution was determined by the method of Abbott \& Grove (1959) at $326 \mathrm{~m} \mu$ in a Unicam SP. 500 spectrophotometer with $1 \mathrm{~cm}$. glass cells.

Training and adaptation to griseofulvin. Eight sets, each of 10 replicates, of Dox medium agars were prepared and to each set griseofulvin in $1 \%(\mathrm{v} / \mathrm{v})$ ethanol was added at the following rates: $1,10,20,40,100,250,500,1000 \mathrm{mg} . / 1$. The organisms 
were grown on these media for 12 subcultures at 15 day intervals (total 180 days). The differences in the diameters of the colonies at the end of the first subculture from those at the end of the 12th subculture were taken as a measure of the degree of training. When a trained mycelium was stable, i.e. when the training was not lost after growth on griseofulvin-free media and when it was transmitted through the spore, then the trained mycelium was considered to be adapted mycelium.

Chitin estimation. Chitin was determined as glucosamine according to the method of Tracey (1955). Oven dried mycelium ( $30-40 \mathrm{mg}$.) was hydrolysed with sulphuric acid and the neutralized hydrolysate assayed for glucosamine by the modified colorimetric method of Elson \& Morgan (1933) using an EEL photoelectric colorimeter at $520 \mathrm{~m} \mu$ (green filter OGRI). A calibration curve was obtained with commercial glucosamine.

\section{RESULTS}

Spectrophotometric determination of the solubility of griseofulvin in Dox liquid medium

Various amounts of griseofulvin in $50 \%(\mathrm{v} / \mathrm{v})$ ethanol in water were incorporated into Dox liquid media to final concentrations from 1 to $100 \mathrm{mg} . / 1 .+1 \%(\mathrm{v} / \mathrm{v})$ ethanol in each. The extinction of the solutions at $326 \mathrm{~m} \mu$ was determined before and after filtration through $5 / 2$ porcelain filters; the results are summarized in Table 1. After these readings the solutions (both filtered and unfiltered) were left for $24 \mathrm{hr}$ and readings again taken; no differences in the values were found.

Table 1. The extinction of Dox liquid medium containing various amounts of griseofulvin

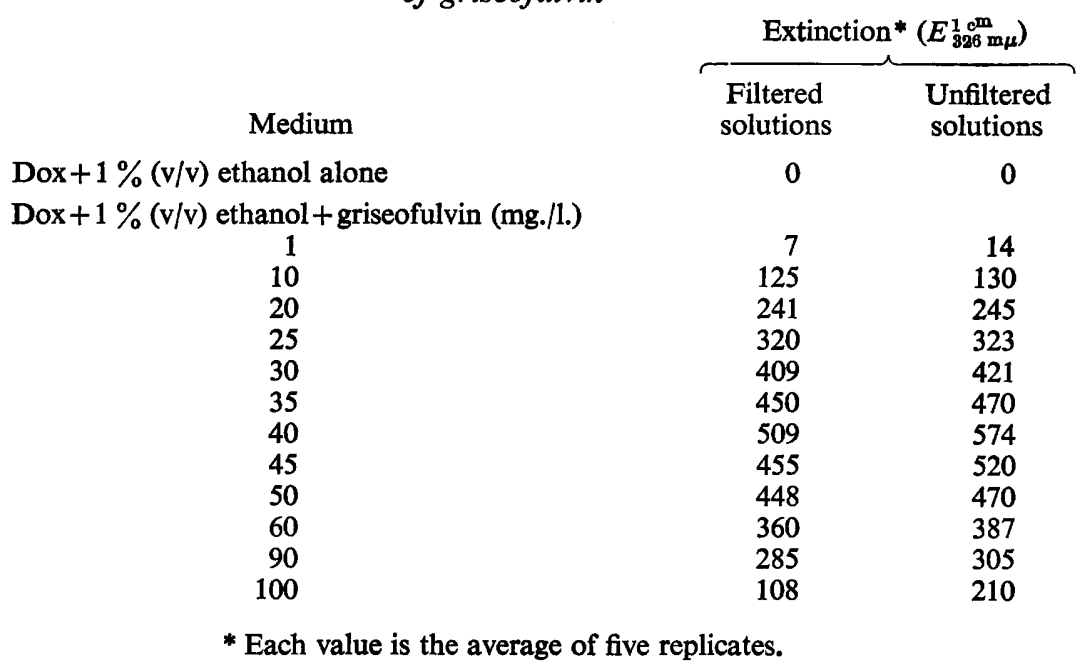

The results show that the amount of griseofulvin in Dox liquid medium $+1 \%$ (v/v) ethanol increased to a maximum at $40 \mathrm{mg}$./1. As the amount added was increased beyond this level, instead of the media having a constant extinction equivalent to that at $40 \mathrm{mg} . / 1$. a gradual decline occurred so that at griseofulvin $100 \mathrm{mg} . / 1$. the medium had an extinction approximately the same as that given when griseofulvin $10 \mathrm{mg} . / 1$. 
was added, the remaining $90 \%$ of the added griseofulvin presumably being in suspension. Since the inhibitory effect of griseofulvin is a function of the amount in solution these results offer an explanation for the unusual growth response of Verticillium to griseofulvin recorded below.

\section{Effect of griseofulvin on the germination of conidia}

Griseofulvin had no effect on the percentage germination of condia; it was $100 \%$ for Verticillium albo-atrum and $V$. dahliae. Depending on the concentration of the griseofulvin, various morphological effects on the hyphae were observed as follows: (1) With no griseofulvin, i.e. Dox medium agar $+1 \%(\mathrm{v} / \mathrm{v})$ ethanol, the germ tubes of both species grew rapidly, were long, regularly branched and their tips appeared normal. (2) Griseofulvin $1 \mathrm{mg}$./1., no response. (3) Griseofulvin $10 \mathrm{mg}$./1., germ tubes of both species were waved, curled and their tips had often grown back on themselves; slight stunting of growth occurred. (4) Griseofulvin $20 \mathrm{mg} . / 1$., germ tubes of both species curled, waved and were torulose with spatulate tips; noticable inhibition of longitudinal extension occurred, the hyphae being shorter and thicker than those on control media. (5) Griseofulvin $40 \mathrm{mg}$./l., germ tubes of both species severely stunted, gnarled, torulose and extremely distorted (P1. 1, fig. 1). (6) Griseofulvin 80 and 100 $\mathrm{mg}$./l., similar effects to $10 \mathrm{mg}$./l., presumably because the same amount of griseofulvin was in solution.

\section{Effect of griseofulvin on growth in Dox liquid media}

The effect of various added amounts of griseofulvin on the growth of Verticillium albo-atrum and $V$. dahliae in Dox liquid medium is summarized in Table 2. With both isolates, increasing concentrations of griseofulvin progressively inhibited development, reaching a maximum effect at $20-40 \mathrm{mg}$. $/ 1$. However, as the amount of added griseofulvin was increased beyond this value, a progressive apparent stimulation of growth took place until at 100-250 mg./1. the mycelial dry-weight values approximated to those at $10 \mathrm{mg}$./1.; from $250-1000 \mathrm{mg}$./1. a further gradual increase in the dry weight value occurred,

The average final $\mathrm{pH}$ values of the culture media after growth of the organisms are indicated in Table 2 . There was the least drift to alkalinity at the point of maximum inhibition. Thick gelatinous mycelial mats pigmented with resting bodies were produced in the control cultures, but in the presence of griseofulvin in excess of $1 \mathrm{mg} . / 1$. the growth of both organisms was diffuse and appeared as small separate colonies. With Verticillium dahliae the griseofulvin cultures had a 'frog-spawn' like appearance, due to the microsclerotia of the small surface colonies being surrounded by hyaline mycelium. Griseofulvin had no effect apparently on the morphology of the resting mycelium of $V$. albo-atrum or on the microsclerotia of $V$. dahliae.

Microscopic examination of the mycelium of both isolates grown at the various griseofulvin additions showed morphological abnormalities. At griseofulvin $1 \mathrm{mg} . / 1$, slight waving of the hyphae occurred; at $10 \mathrm{mg}$./1. the hyphae were more intensely waved, curled and often contained large intercalary cells which resembled chlamydospores but lacked thickened walls (P1. 1, fig. 2). At 20-40 mg./1. (the amount for maximum inhibition), the hyphae were gnarled, torulose and contained many chlamydospore-like cells. At greater than $20-40 \mathrm{mg}$./1. the morphological abnormalities became 
gradually less severe until at $100-250 \mathrm{mg}$./l. and above, they were like those in mycelium grown at $10 \mathrm{mg} . / 1$.

This growth response to griseofulvin of these two Verticillium species was also found in media with the sucrose concentration raised to $5 \%$. When sucrose was omitted from the Dox liquid media containing griseofulvin, little or no growth occurred, indicating that the fungi were unable to utilize griseofulvin as a carbon source. In further tests where the griseofulvin-containing Dox liquid media were sterilized by filtration (i.e. griseofulvin not autoclaved), similar growth effects were recorded although no increase in the mycelial dry weight occurred with griseofulvin $250-1000 \mathrm{mg}$./1.

Table 2. The effect of griseofulvin on the growth of Verticillium albo-atrum and $V$. dahliae after 15 days in Dox liquid medium

\begin{tabular}{|c|c|c|c|c|}
\hline \multirow[b]{2}{*}{ Medium $\ddagger$} & \multicolumn{2}{|c|}{ V. albo-atrum } & \multicolumn{2}{|c|}{$V$. dahliae } \\
\hline & $\begin{array}{l}\text { Mycelial } \\
\text { dry wt. } \\
\text { (mg.*) }\end{array}$ & $\mathrm{pH} \dagger$ & $\begin{array}{l}\text { Mycelial } \\
\text { dry wt. } \\
\text { (mg.)* }\end{array}$ & $\mathrm{pH} \dagger$ \\
\hline Dox $+1 \%(v / v)$ ethanol alone & $48 \cdot 5$ & $7 \cdot 4$ & $119 \cdot 5$ & $8 \cdot 4$ \\
\hline \multicolumn{5}{|c|}{ Dox $+1 \%(v / v)$ ethanol + griseofulvin (mg.ll.) } \\
\hline 1 & $44 \cdot 6$ & $7 \cdot 3$ & $107 \cdot 7$ & $8 \cdot 1$ \\
\hline 10 & 38.5 & 7.0 & $52 \cdot 8$ & $7 \cdot 4$ \\
\hline 20 & $34 \cdot 0$ & 6.8 & $44 \cdot 1$ & 7.2 \\
\hline 40 & $28 \cdot 0$ & 6.7 & $43 \cdot 1$ & 6.9 \\
\hline 60 & $34 \cdot 2$ & $7 \cdot 1$ & $44 \cdot 1$ & $6 \cdot 8$ \\
\hline 80 & 36.9 & 6.8 & 46.8 & 6.8 \\
\hline 100 & 38.5 & 6.9 & $47 \cdot 1$ & $7 \cdot 0$ \\
\hline 250 & $40 \cdot 4$ & 6.9 & $47 \cdot 1$ & 7.2 \\
\hline 500 & $47 \cdot 7$ & $7 \cdot 0$ & $54 \cdot 1$ & $7 \cdot 2$ \\
\hline 1000 & 48.9 & 6.9 & $67 \cdot 1$ & 7.2 \\
\hline
\end{tabular}

* Average of ten replicates.

$\dagger$ The $\mathrm{pH}$ values given represent the average final $\mathrm{pH}$ values of the cultures.

$\ddagger$ Initial $\mathrm{pH}$ of all media $=4 \cdot 3$

At the concentration of griseofulvin for maximum inhibition, griseofulvin particles were seen in the medium, and it was assumed that at this and all higher concentrations the medium was saturated with griseofulvin. By calculation it was apparent that the weight of griseofulvin particles contributing to the mycelial dry weight would only become significant at griseofulvin $250 \mathrm{mg}$./l. and above. It was concluded that the gradual increase in mycelial dry weight at griseofulvin $>250 \mathrm{mg}$./1. was due to griseofulvin particles. However, the mycelial dry-weight increase from griseofulvin $20-40$ to $100-250 \mathrm{mg}$./1. was real and was presumably due to the reduction in the amount of griseofulvin going into solution as observed in the spectrophotometric determination recorded above.

\section{Effect of griseofulvin on growth on Dox medium agar}

The effects of various additions of griseofulvin on the radial expansion of colonies of Verticillium albo-atrum, V.albo-atrum var. and $V$. dahliae are summarized in Table 3. The response of all the organisms was essentially similar in that increased inhibition of radial expansion occurred to a maximum at griseofulvin $40-100 \mathrm{mg}$./1. followed by a slight apparent stimulation of expansion from 100 to $1000 \mathrm{mg} . / 1$. 
At all griseofulvin additions greater than $1 \mathrm{mg}$. $/$. the superficial surfaces of the colonies of $V$. albo-atrum and $V$. albo-atrum var. were irregular in outline, gnarled, convoluted and creamy white in colour although sporulation in both and resting mycelium production in the parent type, $V$. albo-atrum, occurred. Inhibited colonies of $V$. dahliae, however, were identical in gross morphology with those on control media in producing abundantly sporulating white fluffy aerial mycelium and densely aggregated microsclerotia.

Table 3. The effect of griseofulvin on the growth of Verticillium species after 15 days on Dox medium agar

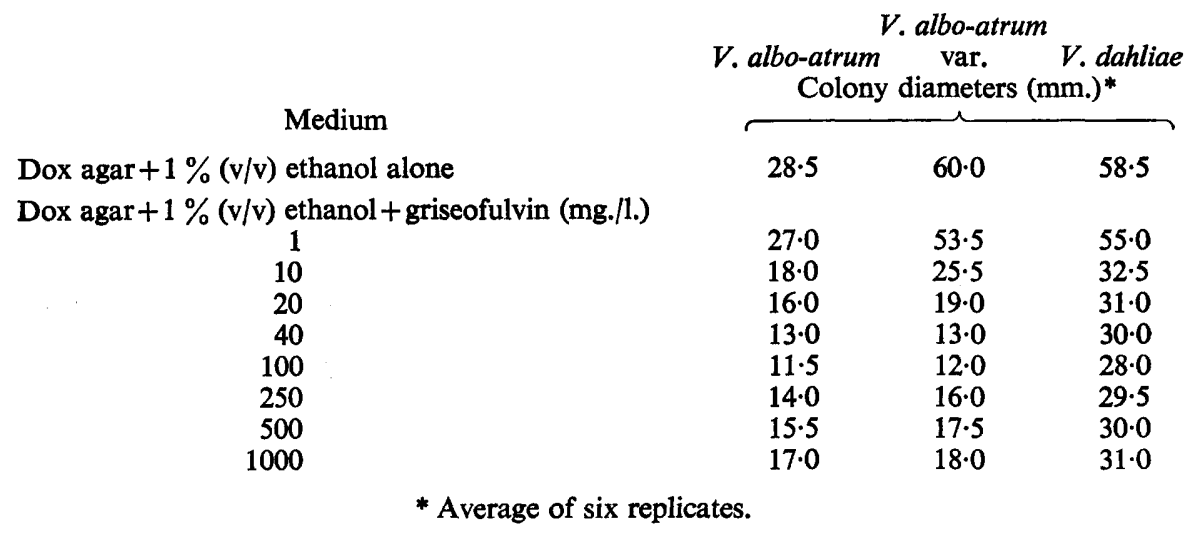

The griseofulvin-containing cultures of all isolates, unlike the controls, exhibited marked aerial growth of hyphae, probably as a result of the suppression of lateral, prostrate growth by the antibiotic, so that the hyphae were raised well above the surface of the agar. An additional characteristic of the inhibited colonies was a considerable radial splitting of the agar.

Microscopic examination of the hyphae in contact with the agar showed the typical morphological abnormalities associated with griseofulvin whereas the aerial mycelium appeared normal.

\section{Training to growth in presence of griseofulvin}

Since the growths of Verticillium albo-atrum var. and $V$. dahliae at the 1 st and 12 th subcultures on Dox medium agar + griseofulvin (see Methods) were almost identical only the results for $V$. albo-atrum are given in Fig. 1. These results suggest that a slight training of both isolates occurred. Throughout the training period, the gross morphology of the colonies of both isolates did not change, although the extensive radial splitting of the agar, observed in earlier subcultures, was only slight at the end of the 12th subculture. Microscopic examination of mycelium at each griseofulvin concentration revealed the usual morphological abnormalities associated with the respective amount of griseofulvin added and no change in the severity of these abnormalities was ever observed.

To test the stability of such training, mycelium from each isolate which had been trained to a particular concentration of griseofulvin was transferred to normal Dox medium agar (i.e. no griseofulvin) for 75 days (five 15-day subcultures) and then placed back for 30 days (two subcultures) on Dox medium agar+added griseofulvin at the 
concentrations to which it had originally been trained. Morphological abnormalities, usually associated with the presence of griseofulvin, were observed in the earlier stages of growth on normal Dox medium agar (1st subculture) but disappeared as the young advancing hyphae grew away from the griseofulvin contained in the inoculum. During the remaining four subcultures on Dox medium agar no morphological abnormalities of the mycelium of either isolate were apparent.

However, on Dox medium agar the diameters of colonies of both isolates were such that they formed growth response curves similar to those produced in the presence of griseofulvin, namely, mycelium trained to griseofulvin $20 \mathrm{mg}$./1. grew more slowly than mycelium trained to $10 \mathrm{mg} . / 1$.

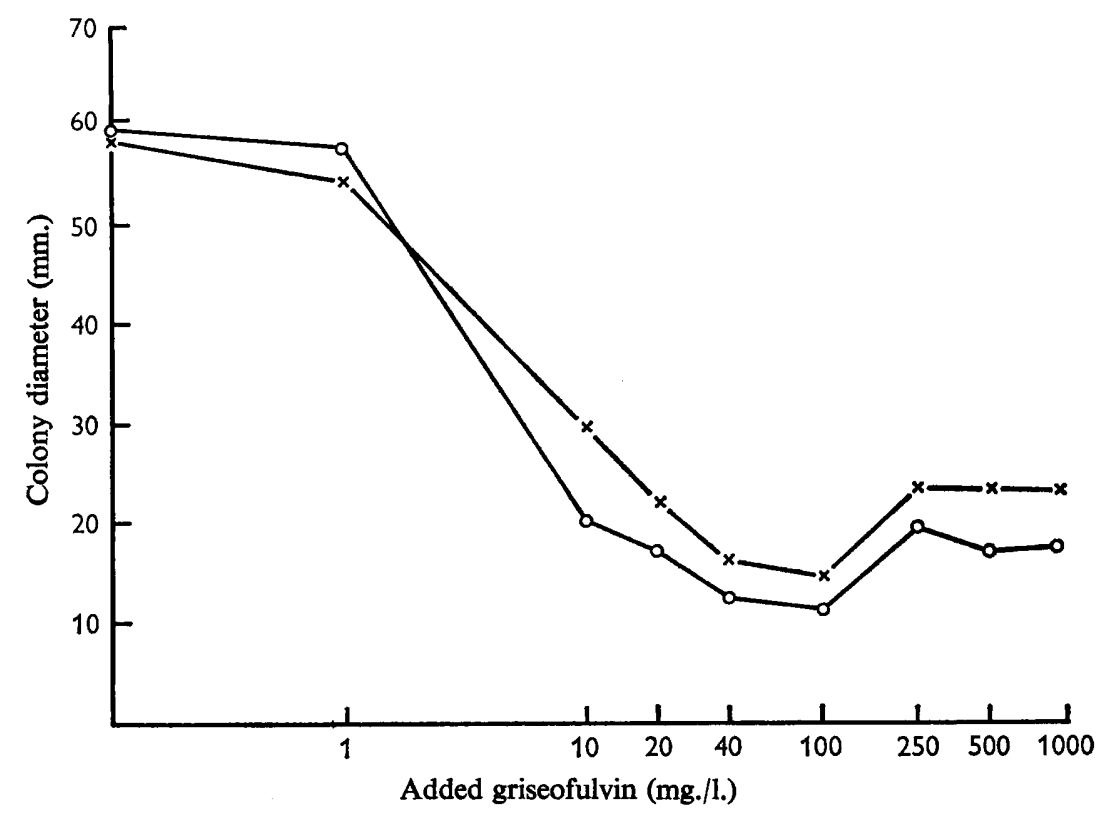

Fig. 1. Growth of Verticillium albo-atrum var. on Dox medium agar $+1 \%(\mathrm{v} / \mathrm{v})$ ethanol and various additions of griseofulvin. __ a a a $\times \longrightarrow$, after 15 days following twelve 15 -day subculture periods.

On transferring previously trained mycelium back to Dox medium agar containing the training concentration of griseofulvin, the morphological abnormalities reappeared, and the diameters of the colonies after two subcultures resembled those of untrained rather than trained mycelium. It was concluded that the slight training of Verticillium albo-atrum var. and $V$. dahliae which developed after prolonged growth on griseofulvincontaining media was unstable and was lost on transfer to media without griseofulvin.

\section{Adaptation to growth in presence of griseofulvin}

During the training experiments, sectors of faster growing mycelium were occasionally produced at the circumference of colonies (Pl. 1, fig. 3) of Verticillium albo-atrum var. (but never of $V$. dahliae) which had grown in the presence of griseofulvin in excess of $1 \mathrm{mg}$./1. The mycelium of such sectors will be for convenience termed adapted. To 
compare the growth of adapted and non-adapted mycelium both Dox medium agars and Dox liquid media with added griseofulvin were used.

Dox medium agar cultures. The results of attempts to determine the effects of various concentrations of griseofulvin on the radial expansion of colonies of adapted mycelium, of mycelium derived from spores of the adapted mycelium, and of the non-adapted mycelium, all of Verticillium albo-atrum var. are summarized in Table 4. In the presence of griseofulvin, colonies from spores and mycelium of the adapted isolate grew at the same rate, and faster than the non-adapted mycelium. In the absence of griseofulvin, however, the diameters of the colonies of the non-adapted mycelium were greater than those of the adapted mycelium. The adapted mycelium grew as smooth flat colonies with faint radiating furrows on a white fairly fluffy surface of slightly sporulating aerial mycelium. The mycelium on media with griseofulvin in excess of $1 \mathrm{mg}$./1. was curled and waved, and although the hyphae were not gnarled they still produced some intercalary swellings at the higher concentrations. The gross morphology and microscopic morphology of the non-adapted mycelium at the various griseofulvin concentrations was similar to that previously described.

Table 4. The effect of griseofulvin on the growth of the adapted mycelium, mycelium derived from spores of this adapted mycelium and on non-adapted mycelium of Verticillium albo-atrum var., after 15 days.

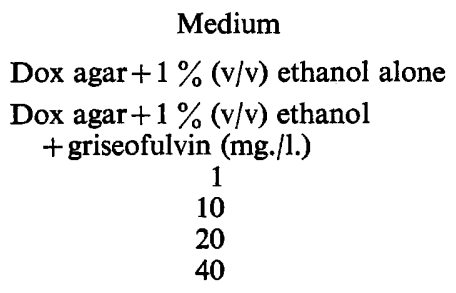

\begin{tabular}{|c|c|c|c|c|}
\hline $\begin{array}{l}\text { Adapted } \\
\text { mycelium }\end{array}$ & $\begin{array}{l}\text { Mycelium } \\
\text { from } \\
\text { spores of } \\
\text { adapted } \\
\text { mycelium }\end{array}$ & $\begin{array}{c}\text { Non- } \\
\text { adapted } \\
\text { mycelium }\end{array}$ & $\begin{array}{l}\text { Adapted } \\
\text { mycelium }\end{array}$ & $\begin{array}{c}\text { Non- } \\
\text { adapted } \\
\text { mycelium }\end{array}$ \\
\hline \multicolumn{3}{|c|}{$\begin{array}{l}\text { Colony diameter on Dox } \\
\text { medium agar }(\mathrm{mm} .)\end{array}$} & \multicolumn{2}{|c|}{$\begin{array}{l}\text { Mycelial dry weight } \\
\text { (mg.) }\end{array}$} \\
\hline $49 \cdot 0$ & $48 \cdot 0$ & $55 \cdot 0$ & 112.5 & $97 \cdot 1$ \\
\hline 48.0 & 48.0 & 50.5 & $91 \cdot 4$ & $78 \cdot 3$ \\
\hline $33 \cdot 0$ & 30.5 & 18.0 & $45 \cdot 2$ & \\
\hline 28.0 & 27.0 & 14.5 & $37 \cdot 0$ & $24 \cdot 2$ \\
\hline $24 \cdot 0$ & $23 \cdot 5$ & $11 \cdot 0$ & 37.5 & $21 \cdot 1$ \\
\hline
\end{tabular}

Dox medium liquid cultures. The effects of griseofulvin on the growth of the adapted and non-adapted mycelium in Dox liquid media are summarized in Table 4. Both isolates produced approximately the same amount of mycelium on the control media without griseofulvin. In the presence of griseofulvin the growth of both isolates was progressively inhibited by increasing additions of griseofulvin to $20-40 \mathrm{mg}$. $/ 1$., but the adapted mycelium grew better than did the non-adapted.

Both isolates developed as thick gelatinous mycelial mats on the media without griseofulvin but in the presence of griseofulvin the adapted isolate gave compact mycelial mats in contrast to the non-adapted isolate which formed small separate colonies showing no tendency to form mats.

Examination of mycelium grown in the presence of griseofulvin showed the following morphological abnormalities: with griseofulvin $10 \mathrm{mg}$./1. the mycelium of the non- 
adapted isolate was curled, waved stunted and torulose, whereas mycelium of the adapted isolate was only slightly waved and extreme hyphal distortion was not seen. With griseofulvin $20 \mathrm{mg}$./l. the mycelium of the non-adapted isolate was extremely distorted (P1. 1, fig. 4) but the mycelium of the adapted isolate was similar to the appearance shown at $10 \mathrm{mg}$./1. (Pl. 1, fig. 5). With griseofulvin $40 \mathrm{mg}$./l. extreme hyphal distortion and malformation appeared in the mycelium of the non-adapted isolate, whereas the mycelium of the adapted isolate, although showing curling and waving, never showed extreme distortion.

To test the stability of the adapted mycelium, the adapted and non-adapted isolates were grown for 75 days (five 15-day subcultures) on Dox medium agar alone. At each subculture, a sample of mycelium of each isolate was transferrred to griseofulvin-containing Dox medium agar. Since in the presence of griseofulvin the growth rate and morphology of the mycelium of the two isolates was similar to that described above, the conclusion may be drawn that no loss of adaptation occurred. Similarly, stock test tube cultures of the adapted isolate kept for 9 months on Dox medium agar still showed no loss of adaptation.

To test the effect of griseofulvin on chitin production in adapted and non-adapted strains of Verticillium albo-atrum var. mycelia of both strains were each separately grown in Dox liquid medium $+1 \%(\mathrm{v} / \mathrm{v})$ ethanol and in Dox liquid medium $+1 \%(\mathrm{v} / \mathrm{v})$ ethanol with added griseofulvin 10 and $40 \mathrm{mg}$. $/ 1$. The mycelium from each treatment was harvested and separately analysed for chitin determined as glucosamine. Three separate analyses were done on each batch of mycelium. The results (Table 5) suggest that whereas the glucosamine content of the cell walls of the non-adapted mycelium increased with increasing griseofulvin concentration, the glucosamine content of the walls of the adapted isolate was almost unaffected by the presence of griseofulvin.

Table 5. The effect of griseofulvin on chitin synthesis (as \% glucosamine) in isolates of Verticillium albo-atrum var. adapted and non-adapted to griseofulvin

\begin{tabular}{|c|c|c|}
\hline & Medium in which mycelium was grown & $\begin{array}{l}\text { Glucosamine- } N \text { in } \\
\text { dry mycelium (\%) }\end{array}$ \\
\hline \multirow[t]{2}{*}{ Non-adapted isolate } & Dox liquid medium $+1 \%(v / v)$ ethanol alone & $0.089 *$ \\
\hline & $\begin{array}{c}\text { Dox liquid medium }+1 \%(\mathrm{v} / \mathrm{v}) \text { ethanol }+ \\
\text { griseofulvin }(\mathrm{mg} . / \mathrm{l} .) \\
10 \\
40\end{array}$ & $\begin{array}{l}0.17 \\
0.25\end{array}$ \\
\hline \multirow[t]{2}{*}{ Adapted isolate } & Dox liquid medium $+1 \%(v / v)$ ethanol alone & $0 \cdot 12$ \\
\hline & $\begin{array}{c}\text { Dox liquid medium }+1 \%(\mathrm{v} / \mathrm{v}) \text { ethanol }+ \\
\text { griseofulvin }(\mathrm{mg} . / 1 .) \\
10 \\
40\end{array}$ & $\begin{array}{l}0.094 \\
0 \cdot 16\end{array}$ \\
\hline
\end{tabular}

* Each analysis is the average of three batches of mycelium each of dry weight $35-40 \mathrm{mg}$.

\section{DISCUSSION}

The observation that griseofulvin had an effect both on the morphology of the hyphae of the Verticillium species tested, and on their growth as measured by radial expansion of colonies and mycelial dry weight increases, is in agreement with the report of Brian (1949) that Verticillium albo-atrum was sensitive to griseofulvin $1 \mathrm{mg} . / 1$. 
Higher concentrations of griseofulvin induced in $V$. albo-atrum and $V$. dahliae the formation of intercalary chlamydospore-like swellings apparently similar to those described by Brian (1960) in Fusarium species.

Although Napier et al. (1956) reported that Verticillium albo-atrum and V. dahliae differed in their response to various concentrations of griseofulvin, as judged by the severity of morphological abnormalities in the hyphae, in the present work both species reacted similarly in that the mycelia of both were much distorted at high concentrations. However, the gross appearance of the colonies of the two species was different on Dox medium agar containing griseofulvin: the surface of cultures of $V$.albo-atrum was gnarled and convoluted, whereas that of $V$. dahliae was more like the controls without griseofulvin, in that it had a smooth appearance.

The peculiar solubility characteristic of griseofulvin in which approximately the same amount went into solution at griseofulvin $100 \mathrm{mg}$./ 1 . as at $10 \mathrm{mg}$./1. may to some extent explain the result obtained by Rhodes (1962) who reported that the uptake of griseofulvin by leaves decreased rapidly with concentration; $73 \%$ was retained at griseofulvin $20 \mathrm{mg} . / 1$. but only $1 \%$ at $5000 \mathrm{mg} . / 1$.

The loss of resistance to griseofulvin of trained mycelium of Verticillium albo-atrum and $V$. dahliae after a period of growth in the absence of griseofulvin was similar to that reported by Brian (1960) with Botrytis allii, by Bartlett (1959) and by Parry \& Wood $(1958,1959 a, b)$ with other fungi to other inhibitors. Using dermatophytic fungi, however, Aytoun, Campbell, Napier \& Seiler (1960), and Rosenthal \& Wise (1960) found that resistance to griseofulvin obtained in training experiments was stable and possibly resulted from the selection of mutants.

Brian (1960) kept colonies of Botrytis allii on a nutrient agar medium containing griseofulvin for several weeks, but never observed any tendency for colonies or sectors of colonies to overcome the inhibition. During the training experiments reported here sectors of faster growing mycelium were occasionally produced at the periphery of colonies of Verticillium albo-atrum var. (but never of $V$. dahliae) which had grown in the presence of griseofulvin $>1 \mathrm{mg}$./ 1 . This mycelium was considered to be adapted since it was stable, and the adaptation was not lost after prolonged growth on griseofulvin-free media. The fact that the adaptation was transmitted through the spore suggests that it was based on mutation.

As a result of the abnormalities in the hyphae, the radial growth of fungal colonies on agar containing griseofulvin may be restricted (Brian, 1960). Adapted mycelium of Verticillium albo-atrum was not severely distorted even at high concentrations of griseofulvin $(40 \mathrm{mg} . / 1$.) and grew faster in the presence of the griseofulvin than did non-adapted mycelium; the reverse was true in the absence of the griseofulvin. Similar morphological responses were observed in Dox liquid medium experiments and although the adapted mycelium appeared more normal than did the non-adapted, the decrease in development of both isolates was considerable, suggesting that inhibition of growth and the morphological effects of the griseofulvin are separate phenomena.

The chitin content (as \% glucosamine) of the cell walls of the adapted and nonadapted isolates suggested that griseofulvin stimulated the production of excess chitin only in the non-adapted isolate. Bent \& Moore (1966), however, found no differences in the composition of isolated walls of Botrytis allii after growth in the presence of griseofulvin, although overall increases in cell wall material occurred.

The diminution in the morphological effects shown by the adapted isolate may be a 

Journal of General Microbiology, Vol. 46, No. 2

Plate 1
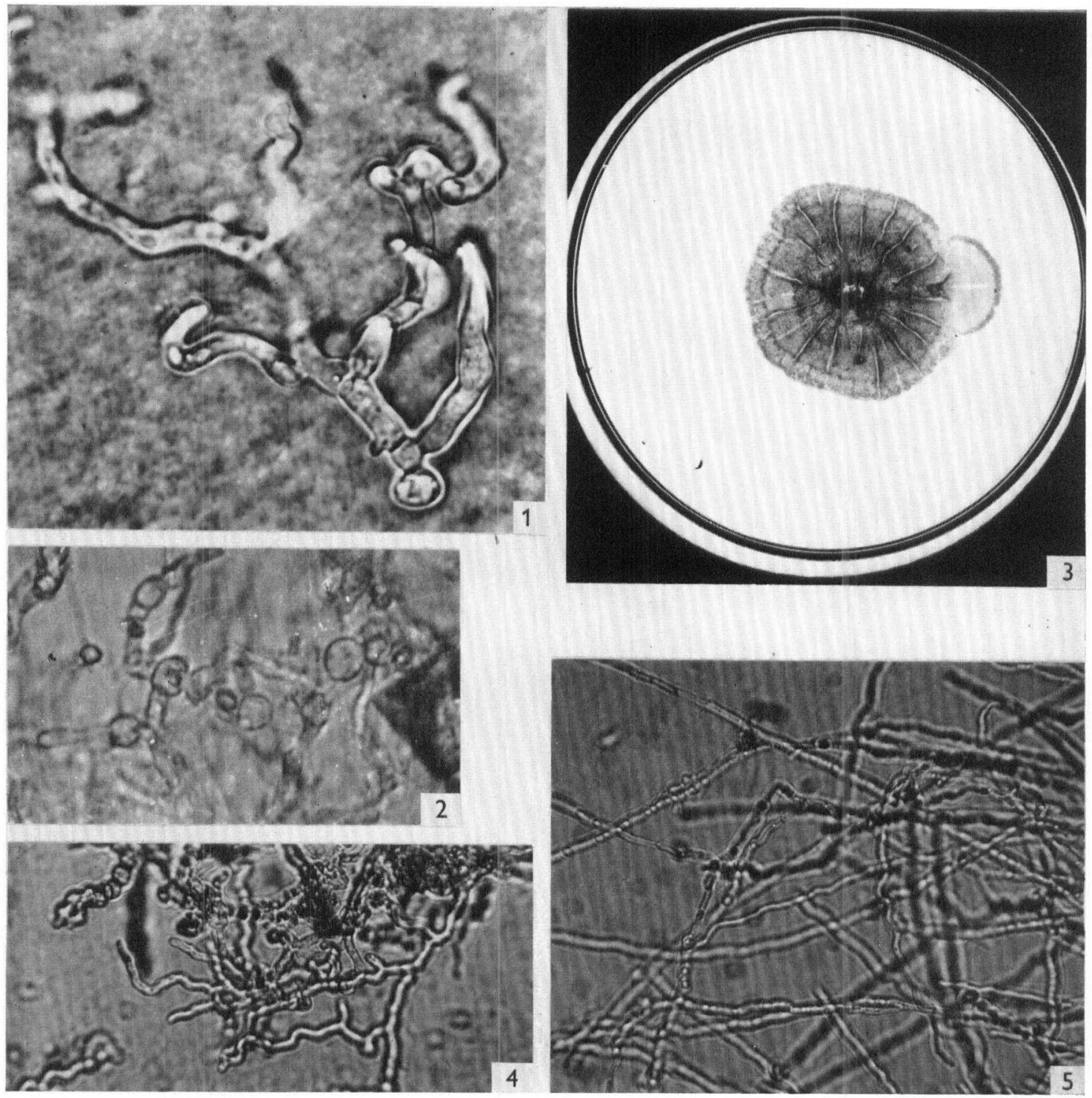
reflexion of a mechanism which prevents griseofulvin from disturbing the morphogenetic system. It would appear unlikely that this is because the isolate breaks down the griseofulvin, for although its enzymic breakdown by various fungi has been reported (Abbott \& Grove, 1959; Boothroyd, Napier \& Somerfield, 1961), El-Nakeeb \& Lampen (1965) found breakdown products only in cultures of griseofulvin sensitive fungi and suggested that uptake of the antibiotic was necessary for degradation to occur.

\section{REFERENCES}

Aвbotr, M. T. J. \& Grove, J. F. (1959). Uptake and translocation of organic compounds by fungi. II. Griseofulvin. Exp. Cell Res. 17, 105.

AYToun, R. S. C. (1956). The effects of griseofulvin on certain phytopathogenic fungi. Ann. Bot., Lond. 20, 297.

Aytoun, R. S. C., Campbell, A. H., Napier, E. J. \& Seiler, D. A. L. (1960). Mycological aspects of the action of griseofulvin against dermatophytes. Arch. Derm. 81, 650.

Bartlett, G. W. (1959). Gain and loss of resistance in the fungus Penicillium roqueforti Thom. Proc. R. Soc. B 150, 120.

BENT, K. J. \& Moore, R. H. (1966). The mode of action of griseofulvin. Symp. Soc. gen. Microbiol. 16, 82,

BoOthroYd, B., NAPIER, E. J. \& Somerfield, G. A. (1961). The demethylation of griseofulvin by fungi. Biochem. J. 80, 34.

Brian, P. W. (1949). Studies on the biological activity of griseofulvin. Ann. Bot., Lond. 13, 59.

Brian, P. W. (1960). Griseofulvin. Trans. Brit. mycol. Soc. 43, 1.

Brian, P. W., Curtis, P. J. \& Hemming, H. G. (1946). A substance causing abnormal development of fungal hyphae, produced by Penicillium janczewskii Zal. I. Biological assay, production and isolation of 'curling factor'. Trans. Brit. mycol. Soc. 20, 173.

EL-NAKeEB, M. A. \& LAMPen, J. O. (1965). Uptake of ${ }^{3} \mathrm{H}$-griseofulvin by micro-organisms and its correlation with sensitivity to griseofulvin. J. gen. Microbiol. 39, 285.

Elson, L. A. \& MoRGAN, W. T. J. (1933). A colorimetric method for the determination of glucosamine and chondrosamine. Biochem. J. 27, 1824.

Grove, J. F. \& MCGowan, J. C. (1947). Identity of griseofulvin and 'curling factor'. Nature, Lond. $160,574$.

NAPIER, E. J., TuRner, D. I. \& Rhodes, A. (1956). The in vitro action of griseofulvin against pathogenic fungi of plants. Ann. Bot., Lond. 20, 461 .

OXFord, A. E., RAISTRICK, H. \& SimONART, P. (1939), Studies in the biochemistry of micro-organisms. 60. Griseofulvin, a metabolic product of Penicillium griseofulvum Dierckx. Biochem. J. 33, 240.

PARRY, K. E. \& WoOD, R. K. S. (1958). The adaptation of fungi to fungicides: adaptation to copper and mercury salts. Ann. appl. Biol. 46, 446.

PARRY, K. E. \& WoOD, R. K. S. (1959a). The adaptation of fungi to fungicides: adaptation to captan. Ann. appl. Biol. 47, 1.

PARRY, K. E. \& WoOD, R. K. S. (1959 $\mathrm{b}$ ). The adaptation of fungi to fungicides: adapatation to thiram, ferbam, nabam and zineb. Ann. appl. Biol. 47, 10.

RHODES, A. (1962). Status of griseofulvin in crop protection. In Antibiotics in Agriculture. Ed. by M. Woodbine, p. 101. London; Butterworths.

Rosenthal, S. A. \& Wise, R. S. (1960). Studies concerning the development of resistance to griseofulvin by dermatophytes. Arch. Derm. 81, 684.

TraceY, M. V. (1955). Chitin. In Modern Methods of Plant Analysis, Ed. by K. Paech and M. V. Tracey. Vol. 2, p. 264. Heidelberg: Springer-Verlang.

\section{EXPLANATION OF PLATE}

Fig. 1. Germ tubes developing from a spore of Verticillium albo-atrum on Dox medium agar $+1 \%$ (v/v) ethanol and added griseofulvin $40 \mathrm{mg} . / 1 . \times 1200$.

Fig. 2. Thin-walled chlamydospore-like cells of Verticillium albo-atrum in Dox liquid medium $+1 \%$ (v/v) ethanol and added griseofulvin $20 \mathrm{mg} . / 1 . \times 750$.

Fig. 3. Development of a sector of adapted mycelium in a colony of Verticilium albo-atrum var. on Dox medium agar $+1 \%(\mathrm{v} / \mathrm{v})$ ethanol and added griseofulvin.

Fig. 4. Mycelium of Verticillium albo-atrum non-adapted to griseofulvin. $\times 300$.

Fig. 5. Mycelium of Verticillium albo-atrum adapted to griseofulvin. $\times 300$. 